\title{
Carta del Presidente del Colegio Argentino de Cardioangiólogos Intervencionistas (CACl)
}

\author{
Letter from the President of $\mathrm{CACl}$
}

Revista Argentina de Cardioangiología Intervencionista 2017;8(3):151

Teniendo la posibilidad de difundir las actividades emprendidas a través de nuestra RACI quiero poner en su conocimiento que la comisión CACI-Ministerio de Salud de la Nación ha finalizado el trabajo emprendido con las autoridades del ministerio en la actualización de la normativa 433 que regula nuestra especialidad.

La norma será publicado una vez que sea firmada la Resolución Ministerial.

Entre algunos de los puntos importantes que constan en ella se encuentra la obligatoriedad del control del funcionamiento de las salas de Hemodinamia cada cinco años (certificación de los equipos y salas en funcionamiento) y del control técnico del equipo cada dos años. Esto indudablemente va a asegurar la mejoría en las prácticas que realizamos, tanto en calidad de imagen como en la bioseguridad de la radiación recibida por pacientes y operadores.

Un punto no menor que se ha puesto en discusión es la no obligatoriedad de un standby quirúrgico, llegándose a un acuerdo consensuado sobre el mismo, ante los grandes avances tecnológicos de los últimos años que han modificado en gran medida el funcionamiento de los servicios de cardiología intervencionista.

Días atrás se realizó una asamblea general extraordinaria donde los socios han apoyado el resguardo de fondos de la sociedad en una inversión inmobiliaria que amplíe nuestras instalaciones actuales. Esto nos refleja el compromiso y profesionalidad con la que las distintas comisiones directivas han dirigido nuestro Colegio, haciéndolo sólido y sustentable más allá de los vaivenes económicos de nuestro país. Los invito a todos a sumarse a participar de las Jornadas Científico y Gremiales a realizarse en la ciudad de Salta en el mes de diciembre, para discutir y ponernos al día de las actividades realizadas por cada una de las comisiones que integran nuestra institución.

Les recuerdo que se encuentra en funcionamiento el vademécum de intervencionismo CACI, el cual se ha convertido en una de las herramientas más usadas de nuestro sitio web.

También quiero mencionarles nuevamente que con gran esfuerzo se ha puesto en marcha un fondo solidario por enfermedad disponible para aquellos colegas que lo crean necesitarlo y lo soliciten a la comisión directiva actuante.

En estos últimos días nuestros colegas en la provincia de Córdoba han formalizado un justo reclamo por el detrimento de las prácticas en su región, lo cual atenta con la calidad de las mismas y a lo cual el Colegio se ha sumado, tendiendo a la difusión local y nacional del problema para evitar la suspensión de servicios y lograr una retribución ética mínima de nuestras prácticas.

Por último, quisiera que tengan presente la invitación a nuestras próximas actividades científicas TCT-CACI-SAC y nuestra mesa CACI-TCT, a desarrollarse en la ciudad de Denver, EE.UU., el próximo mes de octubre del 2017, en donde contamos en ambos eventos con invitados internacionales líderes de opinión a nivel global.

Desde ya agradezco el apoyo brindado por todos Uds. en estos intensos años de gestión que nos han permitido seguir avanzando y ver crecer nuestro Colegio cada día más. 